\title{
EFEITOS DE SISTEMAS DE PREPARO DO SOLO NA CULTURA DA SOJA
}

(Glycine max (L.) Merrill) ${ }^{1}$

\section{ALBERTO CARVALHO FILHO ${ }^{2}$, LUÍS C. C. CARVALHO JOSÉ F. CENTURION ${ }^{3}$, ROUVERSON P. DA SILVA ${ }^{4}$, CARLOS E. A. FURLANI ${ }^{6}$}

\begin{abstract}
RESUMO: Com o objetivo de avaliar o efeito de cinco equipamentos de preparo do solo sobre o desenvolvimento e a produtividade da cultura da soja (Glycine max L. (Merril)), foi conduzida uma pesquisa em Latossolo Vermelho distrófico, no município de Uberaba-MG, em delineamento experimental em blocos casualizados, com cinco tratamentos (escarificador, enxada-rotativa, arado de aivecas, arado de discos e grade aradora) e quatro repetições. Os sistemas de preparo do solo não mostraram diferenças para o número médio de dias para a emergência das plântulas, estande final, altura da primeira vagem e produtividade da cultura da soja. Os tratamentos com arado de disco, arado de aivecas e grade aradora proporcionaram as maiores populações iniciais da cultura. A altura das plantas foi afetada pelos sistemas de preparo utilizados, destacando-se o preparo com o arado de aivecas e com a enxada-rotativa, com os maiores e menores valores absolutos, respectivamente.
\end{abstract}

PALAVRAS-CHAVE: altura da planta, altura da primeira vagem, emergência.

\section{EFFECTS OF SOIL TILLAGE SYSTEMS IN SOYBEAN CROP (Glycine max (L.) Merrill)}

ABSTRACT: With the objective of evaluating the effect of five soil tillage equipments in the development and productivity of soybean (Glycine max L. (Merril)), a research in a Haplustox soil was conducted, in the municipal district of Uberaba - MG, Brazil, using randomized blocks, in a split plot scheme, with five treatments (scared, rotary tiller, moldboard plow, disk harrow and disk plow) and four repetitions. The soil tillage systems didn't show differences in the medium number of days of the soybean emergency, final stand, height of the first bean and productivity of the crop. The treatments with disk plow, moldboard plow and disk harrow provided the biggest initial populations of the crop. The plants height was affected by the soil tillage systems, standing out prepares it with the moldboard plow and with the rotary tiller, with the biggest and smaller absolute values, respectively.

KEYWORDS: plant height, height of the first bean, emergency.

\section{INTRODUÇÃO}

A cultura da soja vem se consolidando como a principal cultura do agronegócio brasileiro (DALL'AGNOL, 2002), notadamente na região Centro-Oeste. Dentre os fatores que mais contribuíram para isso, pode-se destacar o desenvolvimento do bem-sucedido pacote tecnológico para a produção de soja na região, com destaque para as novas variedades adaptadas à condição de baixa latitude, e a topografia altamente favorável à mecanização. Isso favorece o uso de máquinas e equipamentos de grande porte, o que propicia economia de mão-de-obra e maior rendimento nas operações de preparo do solo, tratos culturais e colheita; as boas condições físicas dos solos da região, facilitando as operações do maquinário agrícola e compensando, parcialmente, as desfavoráveis características químicas desses solos (EMBRAPA, 2003).

\footnotetext{
${ }^{1}$ Extraído da Tese de Doutorado do primeiro autor junto à UNESP, Jaboticabal -SP.

${ }^{2}$ Prof. Dr., FAZU, Uberaba - MG e FAFRAM, Ituverava - SP, alberto@ fazu.br.

${ }^{3}$ Prof. Dr., Departamento de Solos e Adubos, UNESP, Jaboticabal -SP.

${ }^{4}$ Prof. Dr., Departamento de Engenharia Rural, UNESP, Jaboticabal - SP.

${ }^{5}$ Graduando em Agronomia, UFLA, Lavras - MG

${ }^{6}$ Prof. Adjunto, Departamento de Engenharia Rural, UNESP, Jaboticabal - SP.

Recebido pelo Conselho Editorial em: 13-12-2005

Aprovado pelo Conselho Editorial em: 16-10-2006
} 
Para dada cultura, deve ser considerado o clima da região para a definição da melhor época de semeadura, bem como as condições de solo necessárias para permitirem a adequada deposição das sementes e adubos, e que proporcionem melhor emergência e desenvolvimento das plantas, resultando em maiores produtividades, dentre outros fatores (EMBRAPA, 2001). Apesar de o potencial genético de uma planta ser limitado, o seu comportamento de desenvolvimento está diretamente relacionado com o meio em que se desenvolve e, portanto, é de se esperar que diferentes condicionamentos do solo, impostos pelos mais variados sistemas e métodos de seu preparo, tendam a modificar as condições de desenvolvimento das culturas.

Este trabalho foi realizado com o objetivo de avaliar os efeitos de diferentes sistemas de preparo periódico do solo na cultura da soja, considerando o número médio de dias para emergência de plântulas, a marcha de emergência das plântulas, a população inicial e final da cultura, o índice de sobrevivência, a altura das plantas e da inserção da primeira vagem e a produtividade da cultura.

\section{MATERIAL E MÉTODOS}

O trabalho foi realizado em um Latossolo Vermelho distrófico, textura média, relevo plano (EMBRAPA, 1999) e densidade média na camada arável igual a $1,73 \mathrm{~g} \mathrm{~cm}^{-3}$, no município de Uberaba-MG, e vinha sendo cultivado, por cinco anos consecutivos, com as culturas anuais de milho e sorgo para produção de silagem em sistema de preparo convencional, por meio de grade aradora.

A área experimental está localizada nas coordenadas geográficas $19^{\circ} 44^{\prime} 13$ " de latitude sul e 47 $57^{\prime} 27^{\prime}$ ' de longitude oeste, com altitude de $780 \mathrm{~m}$. O clima da região, segundo classificação de Köeppen, é Aw, tropical quente e úmido, com inverno frio e seco, precipitação e temperatura média anual de $1.474 \mathrm{~mm}$ de $22,6^{\circ} \mathrm{C}$, respectivamente.

O delineamento experimental foi em blocos ao acaso, com cinco tratamentos e quatro repetições, tendo como tratamentos o preparo periódico do solo com escarificador, modelo AST 5/5, marca Tatu-Marchesan, equipado com cinco hastes espaçadas de $390 \mathrm{~mm}$ e desprovido de rolo destorroador, largura de corte de $1.560 \mathrm{~mm}$ e massa de $390 \mathrm{~kg}$; enxada-rotativa equipada com seis flanges, tendo quatro lâminas tipo veloz por flange, largura de corte $900 \mathrm{~mm}$ e massa total de $220 \mathrm{~kg}$; arado de aivecas fixas, modelo AAP, marca Tatu-Marchesan, equipado com duas aivecas recortadas, largura de corte de $900 \mathrm{~mm}$ e massa de $415 \mathrm{~kg}$; grade aradora, de arrasto, modelo GAM 14, marca Tatu-Marchesan, equipada com 14 discos recortados de 609,6 mm (24") x 6,0 mm, espaçados de $230 \mathrm{~mm}$, largura de corte de $1.500 \mathrm{~mm}$ e massa de $1.210 \mathrm{~kg}$, e arado de discos fixos, modelo AF 4, marca Tatu-Marchesan, equipado com quatro discos de 660,4 mm (26") x 4,75 mm, espaçados de $570 \mathrm{~mm}$, largura de corte de $1.230 \mathrm{~mm}$ e massa de $492 \mathrm{~kg}$.

Utilizou-se do trator Ford 6610, 4x2, com potência no motor de $62,5 \mathrm{~kW}(85 \mathrm{cv})$ a $2.400 \mathrm{rpm}$, operando em velocidade média de $5 \mathrm{~km} \mathrm{~h}^{-1}$, para tracionar os arados, o escarificador e a grade, e um trator Agrale 4100, 4x2, com potência de 10,8 kW (14,7 cv) a $2.750 \mathrm{rpm}$, e velocidade média de operação igual a $1,5 \mathrm{~km} \mathrm{~h}^{-1}$, para tracionar a enxada-rotativa.

Cada parcela constituiu-se de uma área de $100 \mathrm{~m}^{2}(10 \mathrm{x} 10 \mathrm{~m})$, separada por carreadores, também de $10 \times 10 \mathrm{~m}$, os quais foram utilizados para regulagens e manobras das máquinas e implementos. Como parcela útil, foram consideradas as três linhas centrais semeadas, excluindo-se 1,5 $\mathrm{m}$ das extremidades $\left(10,50 \mathrm{~m}^{2}\right)$.

Foram coletadas, em maio de 2000, com trado tipo holandês, amostras de solo na camada superficial $(0-20 \mathrm{~cm})$, destorroadas, homogeneizadas, secas em estufa e passadas em peneira de malha de $2 \mathrm{~mm}$ (terra fina seca em estufa), para posterior caracterização química e granulométrica do solo (EMBRAPA, 1997). A calagem e a adubação foram realizadas conforme análise de solo, de acordo com COMISSÃO DE FERTILIDADE DO SOLO DO ESTADO DE MINAS GERAIS (1999). 
O preparo periódico primário do solo foi feito em outubro de 2000, enquanto a semeadura da soja foi realizada utilizando-se de semeadora-adubadora de linhas individuais montada, modelo PHT, da marca Tatu-Marchesan, no dia sete de dezembro do mesmo ano, utilizando-se da cultivar Segurança. O espaçamento entre linhas foi de $45 \mathrm{~cm}$, com profundidade média de semeadura de $0,05 \mathrm{~m}$.

Os arados de discos, de aivecas e o escarificador foram regulados para prepararem o solo à profundidade média de $20 \mathrm{~cm}$, a grade aradora a $13 \mathrm{~cm}$ e a enxada- rotativa, a $8 \mathrm{~cm}$, sendo a grade aradora e a enxada rotativa reguladas para a obtenção de máxima profundidade de corte.

Adotou-se o preparo convencional para os arados e para a grade aradora, sendo realizada a primeira gradagem de nivelamento logo após o preparo primário, e a segunda, antecedendo a semeadura. Para o escarificador, adotou-se o preparo reduzido do solo, sendo realizada apenas uma gradagem de nivelamento, antecedendo a semeadura, enquanto, para a enxada rotativa, o solo não sofreu nova mobilização.

O preparo do solo e a semeadura foram efetuados estando o solo com a umidade gravimétrica média de $16 \%$ e o controle de plantas daninhas foi realizado quimicamente antes da semeadura, sendo complementado por meio de capina manual, 30 dias após a emergência das plântulas.

O comportamento da cultura da soja, em função do emprego de diferentes sistemas de preparo periódico do solo, foi avaliado mediante amostragens e análises descritas a seguir:

A avaliação da emergência das plântulas foi efetuada por meio da contagem diária de todas as plântulas emergidas em cada tratamento, considerando-se como plântula emergida aquela que rompesse o solo, podendo ser vista a olho nu, de algum ângulo qualquer. A contagem foi realizada até que o número total de plântulas se tornasse repetitivo em cada tratamento, por três dias consecutivos, seguindo a metodologia apresentada por SILVA (2002), e, a partir dessas contagens, expressou-se o número médio de dias para a emergência das plântulas, de acordo com a eq. (1).

$$
\mathrm{M}=\frac{[(\mathrm{N} 1 \mathrm{G} 1)+(\mathrm{N} 2 \mathrm{G} 2)+\ldots+(\mathrm{Nn} \mathrm{Gn})]}{(\mathrm{G} 1+\mathrm{G} 2+\ldots+\mathrm{Gn})}
$$

em que,

M - número médio de dias para a emergência das plântulas de soja;

N1 - número de dias decorridos entre a semeadura e a primeira contagem de plântulas;

G1 - número de plântulas emergidas na primeira contagem;

N2 - número de dias decorridos entre a semeadura e a segunda contagem de plântulas;

G2 - número de plântulas emergidas entre a primeira e a segunda contagem;

$\mathrm{Nn}$ - número de dias decorridos entre a semeadura e a última contagem de plântulas, e

Gn - número de plântulas emergidas entre a penúltima e a última contagem.

A determinação da população inicial de plantas foi obtida por meio da contagem do número de plantas existentes na parcela útil ao final do período de emergência, enquanto a determinação da população final foi obtida imediatamente antes da colheita. Os valores tomados em cada parcela foram convertidos em número de plantas por hectare.

A percentagem de sobrevivência de plantas (PS \%) foi obtida, de acordo com SILVA (1992), por meio da eq.(2):

$$
\mathrm{PS} \%=\frac{\mathrm{PF}}{\mathrm{PI}} 100
$$

em que,

PS \% - percentagem de sobrevivência das plantas;

PI - população inicial de plantas, obtida depois de estabilizada a emergência, plantas ha ${ }^{-1}$, e

$\mathrm{PF}$ - população final de plantas, obtida na época da colheita, plantas ha ${ }^{-1}$. 
Para a determinação da altura média das plantas, mediu-se a distância entre a superfície do solo e a inflexão da última folha superior das 25 primeiras plantas da linha central da parcela útil, realizada aos $19 ; 23 ; 30 ; 37 ; 44 ; 51 ; 58$ e 65 dias após a data de semeadura, quando a cultura entrou em florescimento.

A altura média de inserção da primeira vagem foi obtida tomando-se a distância entre a superfície do solo e a primeira vagem das 25 primeiras plantas da linha central de cada parcela útil, realizada na época da colheita.

A avaliação da produtividade foi efetuada realizando-se a colheita manual de todas as plantas, em cada parcela útil. Após a operação de trilha, os grãos foram pesados e deles retiradas amostras para a correção do teor de água a 14\%, base úmida.

Os resultados obtidos foram tabulados e submetidos à análise de variância e, quando o valor do teste de $\mathrm{F}$ se mostrou significativo, a $5 \%$ de probabilidade, aplicou-se o teste de Tukey para comparação entre as médias.

\section{RESULTADOS E DISCUSSÃO}

\section{Número médio de dias para a emergência das plântulas}

Pode-se verificar que os sistemas de preparo periódico do solo não influenciaram significativamente no número médio de dias necessários à emergência de plântulas (Tabela 1) e tampouco na marcha de emergência (Figura 1), o que mostra que as operações de semeadura e de adubação foram bem realizadas. Observações semelhantes foram efetuadas por BOLLER \& CALDATO (2001), ao avaliarem o desenvolvimento da cultura do feijão em três sistemas de preparo (arado de discos + grade leve, escarificador e plantio direto); entretanto, na pesquisa efetuada por SILVA \& GAMERO (1993), em solo classificado como Terra Roxa Estruturada, combinando as ordens de gradagem (antes ou depois da mobilização primária do solo), utilizando nos sistemas de preparo: arado de discos, grade aradora e escarificador, obtiveram menor índice de velocidade de emergência de plântulas e menor população inicial na cultura do feijão ao realizar a gradagem de destorroamento-nivelamento antes da aração.

TABELA 1. Número médio de dias para a emergência das plântulas da população inicial e final da cultura da soja e índice de sobrevivência, em função do sistema de preparo periódico do solo.

\begin{tabular}{lccccc}
\hline & \multicolumn{4}{c}{ Sistemas de Preparo do Solo } \\
\cline { 2 - 6 } & Escarificador & $\begin{array}{c}\text { Enxada- } \\
\text { Rotativa }\end{array}$ & $\begin{array}{c}\text { Arado de } \\
\text { Aivecas }\end{array}$ & $\begin{array}{c}\text { Grade } \\
\text { Aradora }\end{array}$ & $\begin{array}{c}\text { Arado de } \\
\text { Discos }\end{array}$ \\
\hline $\begin{array}{l}\text { Número médio de dias para a } \\
\text { emergência das plântulas }\end{array}$ & $5,73 \mathrm{a}$ & $5,81 \mathrm{a}$ & $6,0 \mathrm{a}$ & $5,72 \mathrm{a}$ & $5,77 \mathrm{a}$ \\
C.V. $=2,4 \%$ & & & & & \\
\hline $\begin{array}{l}\text { População inicial (plantas ha } \\
\text { C. }\end{array}$ & $311.667 \mathrm{~b}$ & $303.333 \mathrm{~b}$ & $328.810 \mathrm{ab}$ & $325.953 \mathrm{ab}$ & $347.857 \mathrm{a}$ \\
$\begin{array}{l}\text { População final (plantas ha }{ }^{-1} \text { ) } \\
\text { C.V.=4,7\% }\end{array}$ & $286.905 \mathrm{a}$ & $289.762 \mathrm{a}$ & $288.333 \mathrm{a}$ & $301.191 \mathrm{a}$ & $301.190 \mathrm{a}$ \\
$\begin{array}{l}\text { Indice de sobrevivência (\%) } \\
\text { C.V. }=3,3 \%\end{array}$ & $92,0 \mathrm{ab}$ & $95,6 \mathrm{a}$ & $87,6 \mathrm{~b}$ & $92,4 \mathrm{ab}$ & $86,6 \mathrm{~b}$ \\
\hline
\end{tabular}

Médias seguidas pela mesma letra, na linha, são iguais estatisticamente, a 5\% de probabilidade, pelo teste de Tukey. 


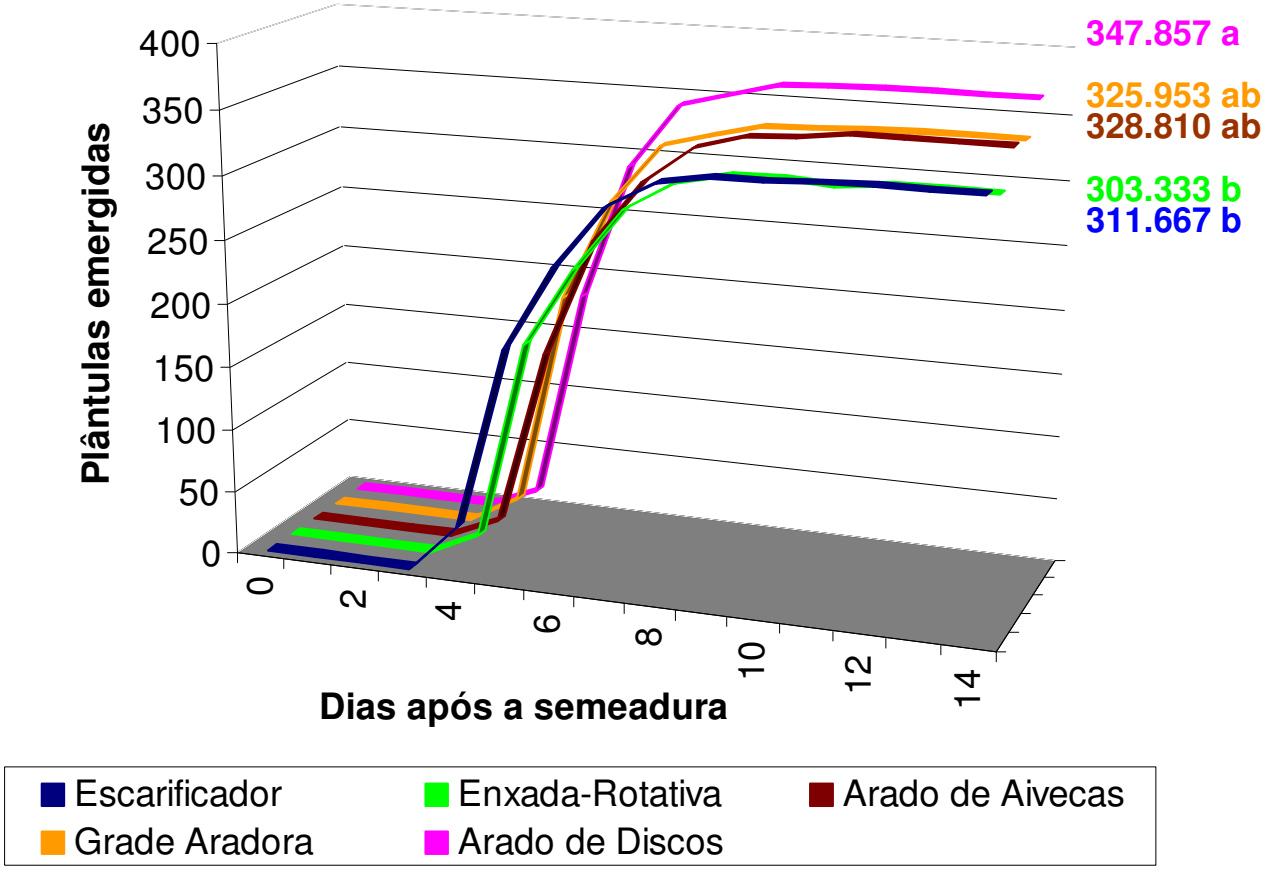

FIGURA 1. Marcha de emergência das plântulas de soja.

\section{População e sobrevivência das plantas}

A análise dos resultados apresentados na Tabela 1 e Figura 2 mostra que o sistema de preparo baseado no arado de discos diferiu dos sistemas com o escarificador e enxada rotativa.

Considerando-se que os equipamentos que dispõem de ferramentas ativas do tipo disco apresentam melhor capacidade de incorporação dos resíduos vegetais existentes na superfície do solo, a cultura da soja parece mostrar-se relativamente sensível aos efeitos da cobertura vegetal. FONTANA et al. (1986), estudando os efeitos do preparo reduzido nas condições de superfície do solo e emergência da soja, também obtiveram pior emergência para a cultura nos tratamentos com maior cobertura do solo com restos vegetais.

Para a população final, não foram observados efeitos entre os diferentes equipamentos (Tabela 1 e Figura 2). FURLANI et al. (2001), avaliando os efeitos da semeadura direta, do preparo reduzido com o emprego do escarificador e do preparo convencional com o arado de discos, sobre a população final de plantas de milho, em duas velocidades de semeadura $\left(3 \mathrm{~km} \mathrm{~h}^{-1}\right.$ para $\left.5 \mathrm{~km} \mathrm{~h}^{-1}\right)$, não observaram os efeitos dos diferentes equipamentos de preparo do solo.

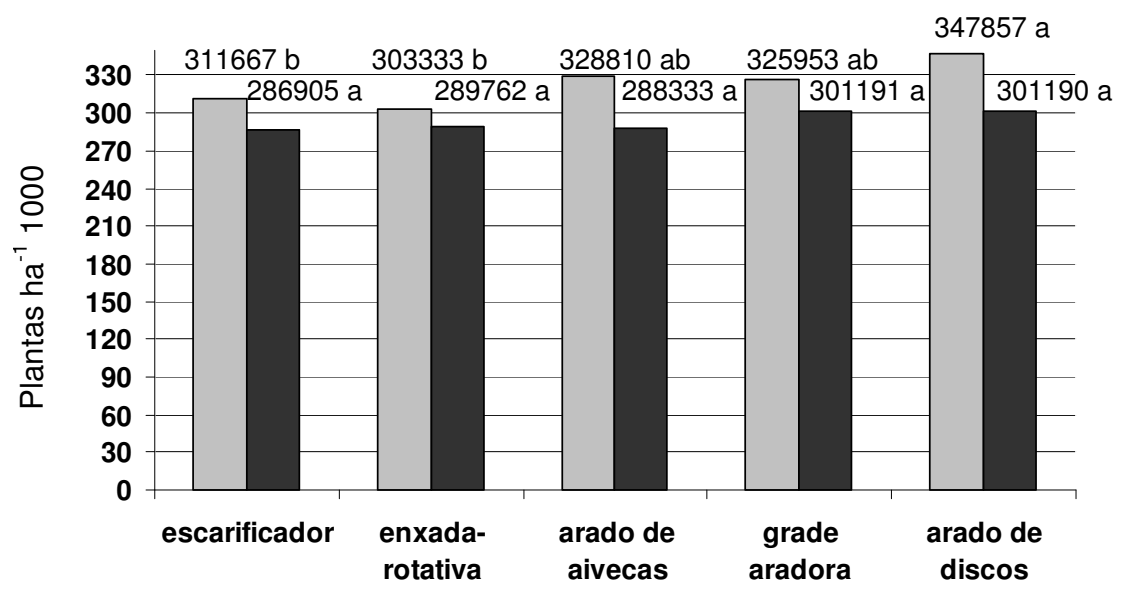

$\square$ População inicial $\square$ População final

FIGURA 2. População inicial e final da cultura da soja (plantas $\mathrm{ha}^{-1}$ ), em função do sistema de preparo periódico do solo. 
Se forem observados os valores absolutos, destacam-se, com o maior número de plantas ha ${ }^{-1}$, ao final do ciclo da cultura, a grade aradora e o arado de discos. SAMPAIO et al. (1989), ERBACK et al. (1992) e COAN (1995), em trabalhos semelhantes, obtiveram a maior população de plantas nos tratamentos com arados.

O índice de sobrevivência de plantas (Tabela 1) foi maior para o tratamento com enxadarotativa, comparado com os arados.

\section{Altura das plantas}

Pode-se verificar, na Tabela 2, que o crescimento das plantas foi afetado pelos equipamentos de preparo periódico do solo apenas a partir de 20 de janeiro, aos 44 dias após a semeadura (DAS), destacando-se, nessa data, o arado de aivecas e a enxada-rotativa, com o maior e o menor valor absoluto $(0,44$ e $0,33 \mathrm{~m})$, respectivamente, representando diferença de $0,11 \mathrm{~m}$. Excluindo-se a avaliação aos 58 DAS, essa tendência foi constatada até o final da avaliação, realizada em 10 de fevereiro, aos $65 \mathrm{DAS}$, em que a diferença na altura, entre esses tratamentos, passou para $0,17 \mathrm{~m}$. SAMPAIO et al. (1989) e COAN (1995) também concluíram que o arado de aivecas se destaca como aquele equipamento que proporciona o melhor crescimento das plantas, em trabalhos realizados com a cultura do milho.

TABELA 2. Valores médios de altura das plantas de soja (m), em função do sistema de preparo periódico do solo.

\begin{tabular}{|c|c|c|c|c|c|}
\hline \multirow{3}{*}{ Data } & \multicolumn{5}{|c|}{ Altura Média de Plantas (m) } \\
\hline & \multicolumn{5}{|c|}{ Sistemas de Preparo do Solo } \\
\hline & Escarificador & Enxada-Rotativa & Arado de Aivecas & Grade Aradora & Arado de Discos \\
\hline $\begin{array}{c}26-12 \\
\text { C.V. }=8\end{array}$ & ${ }_{4 \%} 0,11 \mathrm{a}$ & $0,10 \mathrm{a}$ & $0,10 \mathrm{a}$ & $0,11 \mathrm{a}$ & $0,10 \mathrm{a}$ \\
\hline $\begin{array}{c}30 / 12 \\
\text { C.V. }=6\end{array}$ & $8 \%$ & $0,14 \mathrm{a}$ & $0,14 \mathrm{a}$ & $0,15 \mathrm{a}$ & $0,13 \mathrm{a}$ \\
\hline $\begin{array}{c}06-01 \\
\text { C.V. }=1\end{array}$ & $9 \%^{0,19 a}$ & $0,18 \mathrm{a}$ & $0,22 \mathrm{a}$ & $0,21 \mathrm{a}$ & $0,20 \mathrm{a}$ \\
\hline $\begin{array}{c}13-01 \\
\text { C.V. }=1\end{array}$ & $5 \%$ & $0,21 \mathrm{a}$ & $0,28 \mathrm{a}$ & $0,26 \mathrm{a}$ & $0,25 \mathrm{a}$ \\
\hline $\begin{array}{c}20-01 \\
\text { C.V. }=1 \\
\end{array}$ & $6 \%^{0,35 a b}$ & $0,33 \mathrm{~b}$ & $0,44 \mathrm{a}$ & $0,41 \mathrm{ab}$ & $0,39 \mathrm{ab}$ \\
\hline $\begin{array}{c}27-01 \\
\text { C.V. }=12\end{array}$ & $5 \%{ }^{0,47 a b}$ & $0,44 \mathrm{~b}$ & $0,59 a$ & $0,55 \mathrm{ab}$ & $0,53 \mathrm{ab}$ \\
\hline $\begin{array}{c}03-02 \\
\text { C.V. }=1(\end{array}$ & $0 \%{ }^{0,60 a}$ & $0,58 \mathrm{a}$ & $0,72 \mathrm{a}$ & $0,69 \mathrm{a}$ & $0,67 \mathrm{a}$ \\
\hline $\begin{array}{c}10-02 \\
\text { C.V. }=8 \text {, }\end{array}$ & $\% \quad 0,74 \mathrm{ab}$ & $0,71 \mathrm{~b}$ & $0,88 \mathrm{a}$ & $0,86 \mathrm{ab}$ & $0,84 \mathrm{ab}$ \\
\hline
\end{tabular}

Médias seguidas pela mesma letra, em cada linha, são iguais estatisticamente, a 5\% de probabilidade, pelo teste de Tukey. C.V.- coeficiente de variação.

Observa-se, também, que o escarificador, a grade aradora e o arado de discos apresentam resultados semelhantes aos do arado de aivecas e à enxada-rotativa, como também entre si, mostrando não terem influenciado no desenvolvimento da cultura da soja.

\section{Altura de inserção da primeira vagem}

Os valores da altura de inserção da primeira vagem são apresentados na Figura 3. Observa-se que os diferentes equipamentos de preparo do solo não tiveram influência significativa nos resultados obtidos. O valor médio de $15,9 \mathrm{~cm}$ da altura de inserção da primeira vagem é adequado, estando acima da altura mínima requerida para a colheita mecanizada da cultura. 


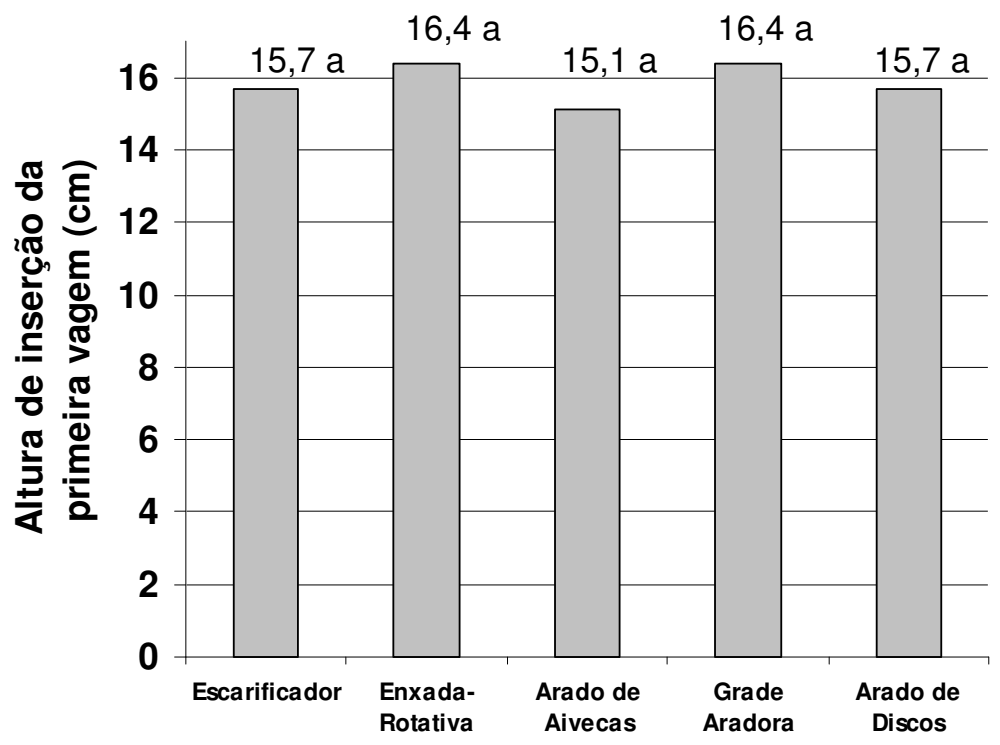

FIGURA 3. Altura de inserção da primeira vagem da cultura da soja (cm), em função do sistema de preparo periódico do solo.

GAVOTTI et al. (2003), comparando o sistema de preparo convencional do solo com o sistema plantio direto, ambos com e sem palha residual, também não verificaram diferenças entre os tratamentos para a altura de inserção da primeira vagem, tendo obtido altura média de $14 \mathrm{~cm}$, inferior, portanto, ao obtido neste trabalho, o que pode ser justificado por diferentes fatores, como, por exemplo, a característica genética da planta e a época de semeadura.

\section{Produtividade da cultura}

Ocorreu forte chuva de granizo durante a fase de enchimento dos grãos, afetando, aparentemente, com a mesma intensidade, toda a área experimental, e isso pode ter causado algum efeito nos tratamentos.

A produtividade de grãos na cultura da soja (Figura 4) não apresentou diferença significativa entre os tratamentos estudados, conforme verificado por GAVOTTI et al. (2003).

MORAES \& BENEZ (1996) não encontraram diferença estatística na produtividade de grãos na cultura do milho em diferentes sistemas de preparo periódico do solo (subsolagem e enxadarotativa, enxada-rotativa, aração, aração e gradagem e semeadura direta), o mesmo ocorrendo com COAN et al. (1982) e ZAFFARONI et al. (1991).

Segundo SIQUEIRA (1999), no preparo baseado em escarificação, o número de plantas de milho emergidas foi maior em relação ao arado de discos, porém a produtividade dessa cultura não apresentou diferença estatística entre os dois métodos de preparo.

Durante o ciclo da cultura, não houve estresse hídrico, entretanto a produtividade obtida foi muito afetada pelas condições climáticas durante a fase final de floração e início de formação de vagens, visto que, na região, a produção média obtida da cultivar Segurança é de $3.000 \mathrm{~kg} \mathrm{ha}^{-1}$, conforme SEDIYAMA et al. (2003). 


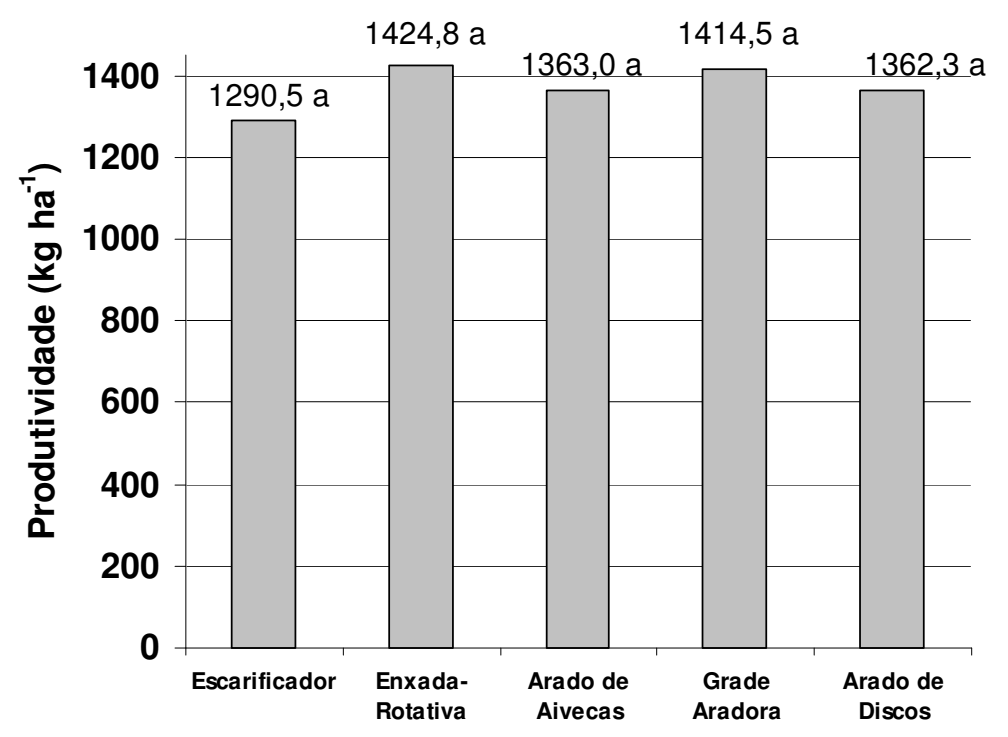

FIGURA 4. Produtividade estimada da cultura da soja, em função do sistema de preparo periódico do solo.

\section{CONCLUSÕES}

Não foram verificadas diferenças para o número médio de dias necessários para a emergência das plântulas de soja, entretanto o sistema de preparo com arado de discos proporcionou as maiores populações iniciais da cultura, quando comparados àqueles no escarificador e na enxada-rotativa.

Devido ao maior índice de sobrevivência de plantas para os tratamentos com enxada-rotativa, escarificador e grade aradora, não foram verificadas diferenças na população final da cultura da soja.

O desenvolvimento das plantas foi afetado pelos sistemas de preparo do solo, destacando-se aqueles que envolveram o arado de aivecas e a enxada-rotativa, com os maiores e os menores valores absolutos, respectivamente.

A produtividade de grãos e a altura de inserção da primeira vagem não sofreram influência dos sistemas de preparo do solo, estando, a altura, acima da mínima requerida para a colheita mecanizada da cultura.

\section{REFERÊNCIAS}

BOLLER, W.; CALDATO, D.E. Desenvolvimento da cultura do feijão (Phaseolus vulgaris L.) em diferentes condições de cobertura e de preparo do solo. Engenharia Agrícola, Jaboticabal, v.21, n.2, p.167-73, 2001.

COAN, O. Sistemas de preparo de solo: efeitos sobre a camada mobilizada e no comportamento das culturas do feijoeiro (Phaseulus vulgaris L.) e do milho (Zea mays L.), conduzidas em rotação. 1995. 138 f. Tese (Livre-Docência em Máquinas Agrícolas) - Faculdade de Ciências Agrárias e Veterinárias, Universidade Estadual Paulista, Jaboticabal, 1995.

COAN, O.; ORTOLANI, A.F.; BANZATTO, D.A. Efeitos de diferentes sistemas de preparo de solo na produtividade de soja (Glycine max L. Merril). Engenharia Agrícola, Botucatu, v.6, n.1, p.7-14, 1982.

COMISSÃO DE FERTILIDADE DO SOLO DO ESTADO DE MINAS GERAIS. Recomendações para o uso de corretivos e fertilizantes em Minas Gerais; 5ª aproximação. Viçosa, 1999. 359 p.

DALL'AGNOL, A. Sem medo de competir. Agroanalysis. São Paulo, v.19, p.42-3, 2002. 
EMBRAPA. Centro Nacional de Pesquisa de Solos. Manual de métodos de análise de solo. 2. ed. Rio de Janeiro, 1997. 212 p.

EMBRAPA. Centro Nacional de Pesquisa dos Solos. Sistema brasileiro de classificação dos solos. Brasília, 1999. 412 p.

EMBRAPA. Reunião de Pesquisa de Soja da Região Central do Brasil. Tecnologia de Produção de Soja da Região Central do Brasil 2001. Londrina, 2001. 267 p. (Documentos, 167).

EMBRAPA. Reunião de Pesquisa de Soja da Região Central do Brasil. Tecnologia de Produção de Soja da Região Central do Brasil 2003. Disponível em:

$<$ http://www.cnpso.embrapa.br/html/sistemasdeproducao/importancia.htm>. Acesso em: 29 jan. 2004.

ERBACH, C.D.; BENJAMIN, J.G.; CRUSE, R.M.; ELAMIN, M.A; MUKHTAR, S.; CHOI, C.-H. Soil and corn response to tillage with paraplow. Transactions of the ASAE, St. Joseph, v.35, n.5, p.1347-54, 1992.

FONTANA, C.; MIRANDA, N.O.; WEISS, A.; DALLMEYER, A.U. Efeito do preparo reduzido nas condições de superfície do solo e emergência de soja (Glycine max L. Merril). In: CONGRESSO BRASILEIRO DE ENGENHARIA AGRÍCOLA, 15., 1986, Botucatu. Anais...Botucatu: Sociedade Brasileira de Engenharia Agrícola, 1986. p.124-44.

FURLANI, C.E.A.; LOPES, A.; REZENDE, L.C.; SOUZA E SILVA, S.S.; LEITE, M.A.S. Influência da compactação do solo na emergência das plântulas de milho a diferentes profundidades de semeadura. Engenharia na Agricultura, Viçosa, v.9, n.3, p.147-53, 2001.

GAVOTTI, F.S.M.; CENTURION, M.A.P.C.; CENTURION, J.F. Comportamento da soja, cultivar IAC FOSCARIM 31, em quatro sistemas de preparo do solo. In: REUNIÃO DE PESQUISA DE SOJA DA REGIÃO CENTRAL DO BRASIL, 25., 2003, Uberaba. Resumos... Uberaba: Embrapa Soja /EPAMIG/ Fundação Triângulo, 2003. p.254-5.

MORAES, M.H.; BENEZ, S.H. Efeitos de diferentes sistemas de preparo do solo em algumas propriedades físicas de uma Terra Roxa Estruturada e na produção de milho para um ano de cultivo. Engenharia Agrícola, Jaboticabal, v.16, n.2, p.31-41, 1996.

SAMPAIO, G.V.; GALVÃO, J.D.; FONTES, A.N.; FIGUEIREDO, M.S.; CARDOSO, A.A. Efeitos de sistemas de preparo do solo sobre o consórcio milho-feijão (Phaseolus vulgaris L.) Revista Ceres, Viçosa, v.36, n.208, p.465-82, 1989.

SEDIYAMA, T.; TEIXEIRA, R.C.; DUTRA, J.H.; GOMES, J.L.L.; SILVEIRA, M.A.S. Cultivar de soja UFVS-2013 em Minas Gerais. In: REUNIÃO DE PESQUISA DE SOJA DA REGIÃO CENTRAL DO BRASIL, 25., 2003, Uberaba. Resumos... Uberaba: Embrapa Soja /EPAMIG/ Fundação Triângulo, 2003. p.100-1.

SILVA, L.G. Ordens de gradagem e sistemas de aração do solo: desempenho operacional, alterações na camada mobilizada e respostas do feijoeiro (Phaseolus vulgaris L.). $1992.180 \mathrm{f}$. Tese (Doutorado em Energia na Agricultura), - Faculdade de Ciências Agronômicas, Universidade Estadual Paulista, Botucatu, 1992.

SILVA, L.G.; GAMERO, C.A. Efeitos de ordens de gradagens e de sistemas de aração sobre o desenvolvimento e produção do feijoeiro. In: CONGRESSO BRASILEIRO DE ENGENHARIA AGRÍCOLA, 22., 1993, Ilhéus. Anais... Ilhéus: Sociedade Brasileira de Engenharia Agrícola, 1993. v.3, p.1520-35.

SILVA, R.P. da. Efeito de rodas compactadoras submetidas a cargas verticais em profundidades de semeadura nas características agronômicas do milho (Zea mays L.). $2002.101 \mathrm{f}$. Tese (Doutorado em Produção Vegetal) - Faculdade de Ciências Agrárias e Veterinárias, Universidade Estadual Paulista, Jaboticabal, 2002. 
SIQUEIRA, R. Sistemas de preparo em diferentes tipos de coberturas vegetais do solo. 1999. 191f. Tese (Doutorado em Energia na Agricultura) - Faculdade de Ciências Agronômicas, Universidade Estadual Paulista, Botucatu, 1999.

ZAFFARONI, E.; BARROS, H.H. de A.; NÓBREGA, J.A.M.; LACERDA, J.T. de; SOUZA JÚNIOR, V.E. de. Efeito de métodos de preparo de solo na produtividade e outras características de milho e feijão no Nordeste do Brasil. Revista Brasileira de Ciência do Solo, Campinas, v.15, n.1, p. 99-104, 1991. 